\title{
Controlled trial of an mHealth intervention to promote healthy behaviours in adolescence (TeenPower): Effectiveness analysis
}

\author{
Pedro Sousa PhD, RN, Associate Professor ${ }^{1,2}$ (D) | \\ Ricardo Martinho PhD, Associate Professor ${ }^{3,4}$ | Catarina I. Reis PhD, Associate Professor ${ }^{3}$ | \\ Sara S. Dias PhD, Associate Professor ${ }^{2,5,6}$ | \\ Pedro J. S. Gaspar PhD, RN, Associate Professor ${ }^{2,5}$ (D) । \\ Maria dos Anjos Dixe PhD, RN, Full Professor, (D) | Luis S. Luis PhD, Associate Professor ${ }^{2,5}$ | \\ Regina Ferreira PhD, MSc, RN, Full Professor 7,8
}

\begin{abstract}
${ }^{1}$ Health Sciences Research Unit: Nursing (UICISA: E), Nursing School of Coimbra (ESEnfC), Coimbra, Portugal

${ }^{2}$ ciTechCare, Centre for Innovative Care and Health Technology, Polytechnic Institute of Leiria, Leiria, Portugal

${ }^{3}$ School of Technology and Management, Polytechnic of Leiria, Leiria, Portugal

${ }^{4}$ Centre for Research in Health Technologies and Information Systems (CINTESIS), University of Porto, Porto, Portugal

${ }^{5}$ School of Health Sciences, Polytechnic Institute of Leiria, Leiria, Portugal

${ }^{6}$ EpiDoC Unit - CEDOC, NOVA Medical School - Universidade Nova de Lisboa (NMS-UNL), Lisboa, Portugal

${ }^{7}$ CIIS-UC, UI-IPSantarém, School of Health Sciences, Polytechnic Institute of Santarém, Santarém, Portugal

${ }^{8}$ UMIS-School of Health Sciences, Santarém, Portugal
\end{abstract}

\section{Correspondence}

Pedro Sousa, Escola Superior de

Enfermagem de Coimbra, Avenida Bissaya

Barreto, Apartado 7001, 3046-851 Coimbra,

Portugal.

Email:pmlsousa@gmail.com

Funding information

This project is co-funded by the European Regional Development Fund, under the Portugal 2020 Program, through COMPETE 2020 (POCI-01-0145-FEDER-23557).

\begin{abstract}
Aim: To evaluate the effectiveness on lifestyle change of an mHealth intervention to promote healthy behaviours in adolescence (TeenPower) and to analyse the predictors of the mHealth intervention effectiveness.

Design: This study is designed as a non-randomized controlled trial with a two-arm structure.

Methods: Adolescents of 12-16-year old were recruited from three school districts, with access to the Internet and smartphone/tablet devices. The intervention group was invited to engage in the mHealth intervention (TeenPower) for 6 months in addition to a school-based intervention. The control group only followed the schoolbased intervention. A repeated measures factorial ANOVA was used and the main effectiveness outcome was the lifestyle change measured by the adolescent lifestyle profile.
\end{abstract}

Results: The outcomes of the mHealth intervention (TeenPower) show a significant effect on nutrition $\left(\eta_{p}^{2}=0.03, p=.03\right)$, positive life perspective $\left(\eta_{p}^{2}=0.04, p=.01\right.$ ), and global lifestyle $\left(\eta^{2}{ }_{p}=0.02, p=.05\right)$, with a dropout rate of $62.1 \%$. The analysis of the effectiveness predictors of the mHealth intervention suggested that older adolescents tended to show a significant increase in the rates of stress management $(r=.40 ; p<.05)$.

Conclusions: Although the considerable dropout rate, the mHealth intervention presented significant impact on multiple lifestyle domains, providing support for the effectiveness of mHealth interventions for health promotion as an add-on to standard interdisciplinary interventions.

Impact: Adolescents must have the necessary and appropriate knowledge for the correct and responsible decision-making regarding their health and lifestyle. Innovative strategies (mHealth intervention) were used to promote healthy behaviours. This 
study evaluates the effectiveness of an mHealth intervention (TeenPower) specifically designed for adolescents. We found a significant impact in several lifestyle domains such as health responsibility, nutrition, positive life perspective, and global lifestyle.

\section{KEYWORDS}

adolescence, case management, controlled clinical trial, health behaviours, mobile health, nursing, obesity

\section{1 | INTRODUCTION}

Comprehensive health promotion strategies, mainly in vulnerable groups such as children and adolescents, are urgent and should be addressed by healthcare institutions and professionals (Guarneri, Brocca, \& Piras, 2017; Velickovski, Orte, Sola, Tabozzi, \& Lafortuna, 2017). Non-communicable diseases (NCD) such as diabetes and cardiovascular diseases are crucial issues for the younger generation. More than two-thirds of preventable adult NCD deaths are associated with risk behaviours that start in adolescence, namely overweight/obesity (Hauerslev \& Allen, 2018).

It is of utmost importance to increase the adolescents' ability to manage their health, adopt healthy behaviours, and use health services more effectively, ensuring their autonomy in the decision-making process (Calvillo, Román, \& Roa, 2015; Guarneri et al., 2017; Karlsson, Andersson, \& Johansson, 2014). That is the main purpose of the TeenPower project: an innovative, interdisciplinary, and multicentre intervention directed to empower adolescents and to promote healthy behaviours, using technological solutions. eHealth literacy skills enable individuals to participate more fully in healthcare activities and play a role in improving their outcomes (Jackson et al., 2019; Jacobs, Lou, Ownby, \& Caballero, 2016). Studies have shown that eHealth literacy is linked to healthier behaviours, weight management, and body image dissatisfaction (Jackson et al., 2019; Sharif \& Blank, 2010).

It is progressively recognized that teamwork and cooperation across health professionals are essential to empower individuals and improve the safety and quality of health care (Courtenay et al., 2018). Single interventions are not likely to be successful for all patients due to the complexity in behaviour change, highlighting the need for a multimodal and interdisciplinary approach (van Middelkoop et al., 2017). A multimodal approach should implement cognitive-behavioural change strategies to improve eating behaviour, reduce energy intake, increase levels of physical activity, and decrease inactivity (Styne et al., 2017).

Information and Communication Technologies (ICT) are important tools for health promotion and have been associated with increased accessibility, equity, effectiveness, and quality of the provided services (Baños, 2011; Baulch, Chester, \& Brennan, 2008). eHealth interventions are associated with a more rational use of health services and support the decision-making process (Modi, Zeller, Xanthakos, Jenkins, \& Inge, 2013; Schoeppe et al., 2017), turning health institutions more efficient, skilled and flexible to meet the needs of patients and professionals (Tate et al., 2013; Turner, Spruijt-Metz, Wen, \& Hingle, 2015). $\mathrm{mHealth}$ solutions sustain the changing role of individuals from a rather passive to a more participative role while improving their responsibility for their health. It raises individuals' awareness of health topics through easy-to-understand information about their health status, thus helping them make more informed decisions on their health (European Commission, 2014).

The remainder of this article is organized as follows: section 2 refers to background studies where we supported the design and execution of our mHealth intervention (TeenPower). Section 3 describes the methods, including its aim, design, sample, execution, data collection, and analysis. In section 4, we report the main results and in section 5 we discuss these results regarding the effectiveness of the intervention. Finally, we conclude the paper in section 6 and point out further research directions.

\section{1 | Background}

The success of a health intervention depends on lifestyle changes and on the maintenance of therapeutic support (Baños, 2011), due to the potential of an ongoing patient-healthcare provider contact to increase the adherence to these changes. The Internet has established as a viable and promising option in this domain (Ahern, Phalen, Le, \& Goldman, 2007; Chen \& Wilkosz, 2014; Nguyen, Kornman, \& Baur, 2011; Turner et al., 2015). The new Global Action Plan to Promote Physical Activity (WHO, 2018) also strikes the importance of digital innovations to support and promote healthy behaviours. This is the framework for action that supported the TeenPower team to take better advantage of the use of ICT and digital platforms for this purpose.

Technological solutions are essential to empower people to be responsible for their health, by providing support and information (Ahern et al., 2007; Enwald \& Huotari, 2010; Nguyen et al., 2011). The citizens' health empowerment by technology (e-empowerment) has the power to reduce the cost of healthcare services and improve health. It can give citizens more control over their well-being and health, empower health professionals and adolescents, and support the development of new treatments (Calvillo et al., 2015; Karlsson et al., 2014). The digital revolution in health may improve and provide safer, better, and sustainable care (Sardi, Idri, \& Fernández-Alemán, 2017; Turner et al., 2015), changing the way the people relates to health professionals and get information on health. 
Nowadays, the challenges and demands that adolescents face create a need for innovative strategies for the promotion of healthy behaviours with the inclusion of mHealth technologies (Kim \& Xie, 2017). mHealth interventions have emerged due to the ubiquity use of mobile devices, mostly smartphones, making it possible to deliver meaningful health information in people's everyday activities (Danaher, Brendryen, Seeley, Tyler, \& Woolley, 2015; European Commission, 2014). This concept of mobility is central for a participatory health care (Cameron, Ramaprasad, \& Syn, 2017), presenting diverse health intervention opportunities that range from disease management to smoking cessation, or weight loss (Afshin et al., 2016; Bert, Giacometti, Gualano, \& Siliquini, 2014; Sousa, Fonseca, Gaspar, \& Gaspar, 2015).

The TeenPower team tested this framework with users, care professionals, and care organizations, adapted to a practice-based research supported by local health stakeholders (school community and health professionals), in the absence of a dynamic and integrated strategy for the promotion of salutogenic adolescent behaviours. This interdisciplinary intervention applied a case management approach, a collaborative process to assess, plan, coordinate, and evaluate care, to meet an individual's health needs (CMSA, 2016).

mHealth interventions towards the adolescent population are growing in number and capitalizing an advantage to improve health behaviours in young populations (Fedele, Cushing, Fritz, Amaro, \& Ortega, 2017; Simons et al., 2018) and, so far, the effectiveness of these interventions has yielded mixed results. Currently, mHealth systems are using a rich user experience that includes games to engage adolescents (Orji, Tondello, \& Nacke, 2018), improve health outcomes, and empower behavioural change (Guarneri \& Perego, 2017).

Presently, there are no clinically validated $\mathrm{mHealth}$ interventions for adolescents in Portugal and few in Europe. International apps aiming to promote healthy behaviours exist, but they are automated and are not managed by healthcare professionals. Therefore, the TeenPower intervention fills this gap and brings us the knowledge that will also support clinical practice and research.

To develop emerging innovative experiences in mHealth interventions, it is crucial to understand health consumers' intention and behaviour (Kim \& Park, 2012), which underscores the importance of the Health Information Technology Acceptance Model (HITAM) adopted for the TeenPower project. However, this model has not been previously tested in a similar setting. User acceptance of technology is the main factor in applying ICT in healthcare services, depending on perceived usefulness, perceived ease of use, and perceived threat (Kim \& Park, 2012).

\section{2 | THE STUDY}

\section{1 | Aim}

This paper evaluates the effectiveness on lifestyle change of an $\mathrm{mHealth}$ intervention to promote healthy behaviours in adolescence
(TeenPower) and analyses the predictors of the mHealth intervention effectiveness. Based on the literature review and the support of the HITAM model (Kim \& Park, 2012), we looked for evidence for the general investigation hypothesis: adolescent lifestyle is positively influenced by the mHealth intervention (TeenPower).

\section{2 | Design}

This paper presents the results of a non-randomized clinical trial (quasi-experimental pre- and post-test design with a control group) that evaluated an innovative mHealth intervention focused to promote healthy behaviours in adolescents, using collaborative and interactive technologies that support a virtual therapeutic community with a game-based approach. The full detailed trial protocol was already published (Sousa et al., 2019). This multicentre controlled trial was conducted to determine the effectiveness of a 6-month complex intervention (Craig et al., 2013). The trial was performed from October 2018-April 2019 at three school districts in Portugal. After a baseline assessment, the adolescents were non-randomly allocated into two groups (experimental group and control group), according to their preference and the study flow diagram (Figure 1).

\section{3 | Sample}

Participants were recruited from three Portuguese school districts, aged between 12- and 16-years old, with easy access to the Internet and smartphone/tablet (inclusion criteria). Exclusion criteria were the inability to communicate in writing and the presence of severe cognitive limitations, evaluated by the school teachers and the interdisciplinary health team.

The experimental group was invited to engage in the $\mathrm{mHealth}$ intervention (described below) and additionally to participate in a structured school-based intervention (face-to-face psycho-educative sessions with nutritional, behavioural, and physical activity counselling). The control group only followed the structured schoolbased intervention (Sousa et al., 2019).

The sample size was calculated according to the power analysis and was based on existing evidence in the literature. We expected to show differences between the groups, estimating a small effect size (0.2) (Sousa, Fonseca, et al., 2015). Bearing in mind the desired statistical power level (0.80) and the level of statistical significance (0.05), a minimum total sample size of 150 adolescents was needed for repeated measures $2 \times 2$ factorial ANOVA. Assuming a high dropout rate and to maximize the statistical power of the study, we decided to expand the initial sample size recruitment to 361 adolescents (Figure 1).

\section{$2.4 \mid$ mHealth intervention (TeenPower)}

The main goals for the implementation of this mHealth intervention directed to adolescents were (a) to monitor individual health 


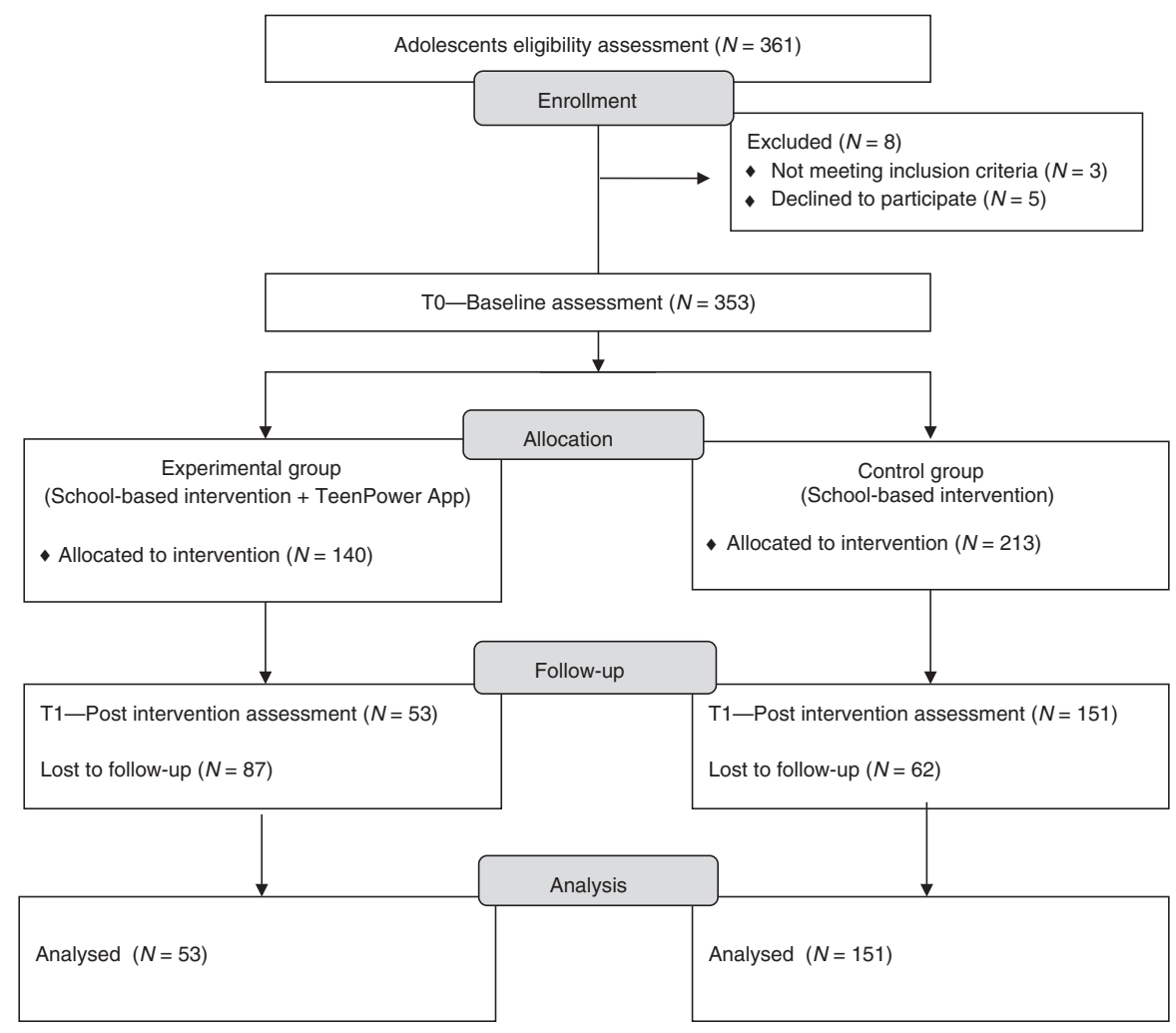

FIGURE 1 TeenPower design and flow diagram indicators, (b) to establish therapeutic interaction based on the adolescent's individual needs, and (c) to establish interactive education regarding adolescent health-promoting behaviours.

The intervention included nutritional, behavioural, and physical activity counselling supported by the mHealth app. The intervention took into account the most recent guidelines on obesity prevention and health promotion among adolescents (Kelishadi \& AziziSoleiman, 2014; WHO, 2012, 2018), the contributions of previous research and used the HITAM Model as a conceptual framework. In addition to the case manager, the intervention also had the direct support of an interdisciplinary team (psychology, nutrition, sport, nursing, informatics, design, among others). Intervention length was 6 months. The e-therapeutic system included (Sousa et al., 2019) the following:

1. TeenPower backoffice: a web-based software application created for health professionals and teachers to support the decision-making process regarding the personalization of the mHealth intervention. The backoffice application contained the following modules: users' management module, social interaction module (private chat and discussion forums), content management system, and showcase contents (videos, images, documents, and daily challenges), data analysis module with interactive charts and filters (dashboard with all the users' monitoring data such as eating habits, physical fitness, physical activity, hydration, and sleep monitoring);

2. TeenPower mobile software application: created for adolescents to provide them with educational resources (infographics, videos, menus, and daily tips), social support (discussion forums, chat, and personalized messages), self-monitoring features (BMI and waist circumference adjusted for age and gender, eating habits, hydration, steps counter, sleep habits, and physical activity records such as push-ups and sit-ups), interactive training modules and motivational tools (positive reinforcement, progression of health behaviours, and biometric data). The structure of the TeenPower app used a game-based learning process, where the adolescent engagement was rewarded with points and progress in a wall of fame.

\subsection{Data collection}

The intervention was evaluated at baseline (TO) and post-intervention (6 months: T1). The main outcomes measured at 6 months were the change in lifestyle and their multiple domains. The following instruments and measures were used in this study:

\subsection{1 | Adolescent lifestyle profile (ALP)}

This instrument measures the frequency of health-promoting behaviours in adolescents. The Portuguese version of ALP (Sousa, Gaspar, Fonseca, Hendricks, \& Murdaugh, 2015) is a 36-item summated behaviour rating scale that employs a 4-point Likert-type response format, structured into seven factors (Health Responsibility, Physical Activity, Nutrition, Positive Life Perspective, Interpersonal 
Relationship, Stress Management, and Spiritual Health). This scale presents a high-reliability score $(\alpha=.87)$, with subscale reliability values between 0.49 and 0.75 . A high ALP score relates to a healthier lifestyle.

\subsection{2 | Body image dissatisfaction}

Body Image perception was measured using a sequence of seven silhouettes (Collins, 1991) that evolve progressively from thinness (1) to overweight (7). Each individual identified the silhouette that best represented his/her body shape and the silhouette that they would desire to have. Body dissatisfaction was estimated by the present minus the desired body shape. Positive scores reveal that the individual is dissatisfied by being heavier than desired; negative scores reveal that the individual is dissatisfied by being lighter than desired; a score of zero reveals satisfaction with body shape. The psychometric properties of this instrument indicate a good concurrent validity in Portuguese children (Coelho, Padez, Moreira, Rosado, \& MourãoCarvalhal, 2013).

\subsection{3 | eHealth literacy}

This was measured by the eHealth Literacy Scale, a self-report tool based on an individual's perception of her or his skills and knowledge within each measured domain related to eHealth literacy. It includes eight items, with two additional items which complement the information (items 1 and 2). Its score ranges from 1-5 and the higher the score, the higher the levels of eHealth literacy. This instrument is validated to the Portuguese population (Tomás, Queirós, \& Ferreira, 2014) and presents a good-reliability score $(\alpha=.84)$.

\section{6 | Validity and reliability}

The design of this controlled trial aimed to minimize the confounding bias of sociodemographic data, assuming that these factors could influence the results of the study. The use of multivariate repeated measure analyses also considered these confounding variables. Baseline differences between the two groups were also analysed to evaluate whether the groups are comparable and homogeneous.

\section{7 | Ethical considerations}

All study adolescents and their legal representatives gave written informed consent, following the ethical principles of the American Psychological Association and the Declaration of Helsinki. Voluntary participation and confidentiality were assured. The study was approved by the ethics committee of the National Data Protection Commission (11465/2017) in 2017 and approved by the Portuguese
Education Ministry (0254300004/2018) in 2018. The trial was also registered in clinicaltrials.gov (NCT03516097).

\section{8 | Data analysis}

Results are presented according to the Transparent Reporting of Evaluations with Non-randomized Designs (TREND) statement. In noninferiority trials as this, the per-protocol analysis is the recommended procedure to explore the effectiveness of a new intervention (Hahn, 2012). Therefore, the analysis only included the participants who benefited from the intervention, namely the participants from the mHealth arm that successfully engaged in the TeenPower mobile app, using the app at least once.

Participants were tracked using ID numbers. Statistical analyses were performed to obtain descriptive statistics and to evaluate the intervention effectiveness. Independent sample $t$ tests and ANOVAs were performed to compare continuous outcomes between groups. The chi-square test was used for nominal variables and Pearson correlations were computed to correlate continuous outcomes.

Repeated measures two-way analyses of variance (ANOVA) were performed to analyse the longitudinal changes in each group and to test the main effects of the intervention period on the same outcomes. The effect sizes were calculated using the partial eta squared $\left(\eta_{p}^{2}\right)$ that indicates the amount of the total variability attributable to a particular factor. All analyses were conducted using bilateral tests and statistical significance of 0.05 . For this purpose, version 24.0 of the SPSS software was used. The predictive effect of sociodemographic (age, gender, and school district) and behavioural data (body image dissatisfaction and eHealth literacy) on the effectiveness of the mHealth intervention was also analysed.

\section{3 | RESULTS}

According to the defined inclusion/exclusion criteria, the eligibility of the 361 adolescents was assessed (Figure 1). The baseline assessment included 353 adolescents: 140 were allocated to the experimental group (TeenPower group) and 213 were allocated to the control group. In the mHealth arm, 87 participants were lost to follow-up, for not having accessed the app at least once or not having completed the final evaluation. In the control group, 62 adolescents were lost to follow-up. Therefore, the post-intervention assessment and analysis included 53 adolescents in the experimental group and 151 adolescents in the control group.

The total of 204 adolescents are mainly women (57.8\%), 12.43 (SD 0.87) years old, with moderate e-health literacy (mean $=3.53, S D$ 0.68 ), little body image dissatisfaction (mean $=0.46, S D 1.11$ ) and a moderate global lifestyle score (mean $=2.72, S D 0.40$ ). Higher scores were found in interpersonal relations (mean $=3.15$, SD 0.56) and positive life perspective (mean $=3.07, S D 0.65)$ and lower scores were found in spiritual health (mean $=1.86, S D 0.72$ ) and health responsibility (mean $=2.38, S D 0.60)$. 
Table 1 presents the descriptive statistics at baseline and the main differences between mHealth and control groups. The two groups can be considered comparable and homogeneous concerning most of the characteristics. However, significant differences were found regarding school district $\left(\chi^{2}=6.70 ; p=.04\right)$.

Regarding the analysis of the effectiveness of TeenPower compared with the standard school-based intervention (Table 2), the general linear models indicated a non-significant main effect of Time on the scores of all lifestyle dimensions (within-subjects' analysis). However, a significant interaction between Time and Groups on the scores of the health responsibility was found, Wilks' Lambda $=0.98, F(1,202)=3.72, p=.05$. Multiple comparisons showed that the mean score of health responsibility in the experimental group increased from the baseline and decreased in the control group $(\Delta$ mean $=0.10, S D 0.59$ vs. $\Delta$ mean $=-0.07$, SD 0.53).

Results also indicated a significant group effect (between-subjects' analysis) on the scores of nutrition, $F(1,202)=5.09, p=.03$, $\eta_{p}^{2}=0.03$, positive life perspective, $F(1,202)=7.44, p=.01$, $\eta_{p}^{2}=0.04$, and global lifestyle, $F(1,202)=4.08, p=.05, \eta_{p}^{2}=0.02$ (Table 2). Multiple comparisons showed that the mean score of nutrition ( $\Delta$ mean $=0.02, S D 0.48$ vs. $\Delta$ mean $=-0.07, S D 0.42$ ), positive life perspective $(\Delta$ mean $=0.04, S D 0.72$ vs. $\Delta$ mean $=-0.07, S D 0.67)$, and global lifestyle $(\Delta$ mean $=0.04, S D 0.40$ vs. $\Delta$ mean $=-0.06, S D$
0.33) increased from the baseline in the experimental group and decreased in the control group.

Considering the baseline differences between groups regarding the adolescents' school districts, we also conducted separate repeated measures analyses (general linear models) of the group effect in each school district (Table 3). Results indicated a significant group effect on the positive life perspective (TeenPower: $\Delta$ mean $=-0.23$, SD 0.75; Control: $\Delta$ mean $=-0.12, S D 0.56$ ) and the stress management (TeenPower: $\Delta$ mean $=0.10, S D$ 0.59; Control: $\Delta$ mean $=-0.03$, $S D$ 0.44) within school district $B$; a significant group effect on the nutrition (TeenPower: $\Delta$ mean $=0.10, S D$ 0.59; Control: $\Delta$ mean $=-0.03$, $S D$ 0.44), the positive life perspective (TeenPower: $\Delta$ mean $=-0.02$, SD 0.53; Control: $\Delta$ mean $=-0.09, S D$ 0.72), the interpersonal relations (TeenPower: $\Delta$ mean $=-0.03, S D$ 0.57; Control: $\Delta$ mean $=0.08$, $S D$ 0.52), the stress management (TeenPower: $\Delta$ mean $=-0.05$, $S D$ 0.46; Control: $\Delta$ mean $=0.04, S D 0.65)$, and the global lifestyle (TeenPower: $\Delta$ mean $=0.05, S D$ 0.37; Control: $\Delta$ mean $=-0.07, S D$ 0.34 ) in school district $C$.

Table 4 presents the results of the univariate analysis on the predictors of effectiveness in the mHealth (TeenPower) group. Results indicated that older adolescents tended to show a significant increase in rates of stress management $(r=.40 ; p<.05)$. The other tested variables presented a non-significant association with lifestyle change.

TABLE 1 Baseline characteristics of the participants of the TeenPower group and control group

\begin{tabular}{|c|c|c|c|c|c|c|}
\hline & \multicolumn{2}{|c|}{ Control group } & \multicolumn{2}{|c|}{ TeenPower group } & $t$ & $p$ \\
\hline Age & 12.60 & 1.01 & 12.40 & 0.86 & 1.63 & .10 \\
\hline Body image dissatisfaction & 0.40 & 1.08 & 0.43 & 1.20 & -0.23 & .82 \\
\hline eHealth literacy & 3.50 & 0.69 & 3.62 & 0.66 & 1.02 & .31 \\
\hline Physical activity & 2.76 & 0.72 & 2.84 & 0.63 & -0.74 & .46 \\
\hline Nutrition & 2.86 & 0.47 & 2.96 & 0.45 & -1.35 & .18 \\
\hline Positive life perspective & 3.02 & 0.63 & 3.20 & 0.70 & -1.79 & .08 \\
\hline Interpersonal relationship & 3.12 & 0.57 & 3.25 & 0.52 & -1.50 & .14 \\
\hline ALP total score & $N$ & $\%$ & $N$ & $\%$ & $\chi^{2}$ & $p$ \\
\hline \multicolumn{7}{|l|}{ Gender } \\
\hline Male & 63.00 & 41.7 & 23.0 & 43.4 & 0.05 & .83 \\
\hline Female & 88.00 & 58.3 & 30.0 & 56.6 & & \\
\hline \multicolumn{7}{|l|}{ School district } \\
\hline School A & 48.00 & 31.8 & 21.0 & 39.6 & 6.70 & .04 \\
\hline School B & 25.00 & 16.6 & 15.0 & 28.3 & & \\
\hline School C & 78.00 & 51.7 & 17.0 & 32.1 & & \\
\hline
\end{tabular}

Abbreviations: ALP, adolescent lifestyle profile; $t$, Student's $t$ test statistic; $\chi^{2}$, Chi-squared test statistic. Bold indicates statistically significant $p<.05$. 
TABLE 2 Comparison of lifestyle change between the TeenPower group and control group: within-subjects and between-subjects analysis

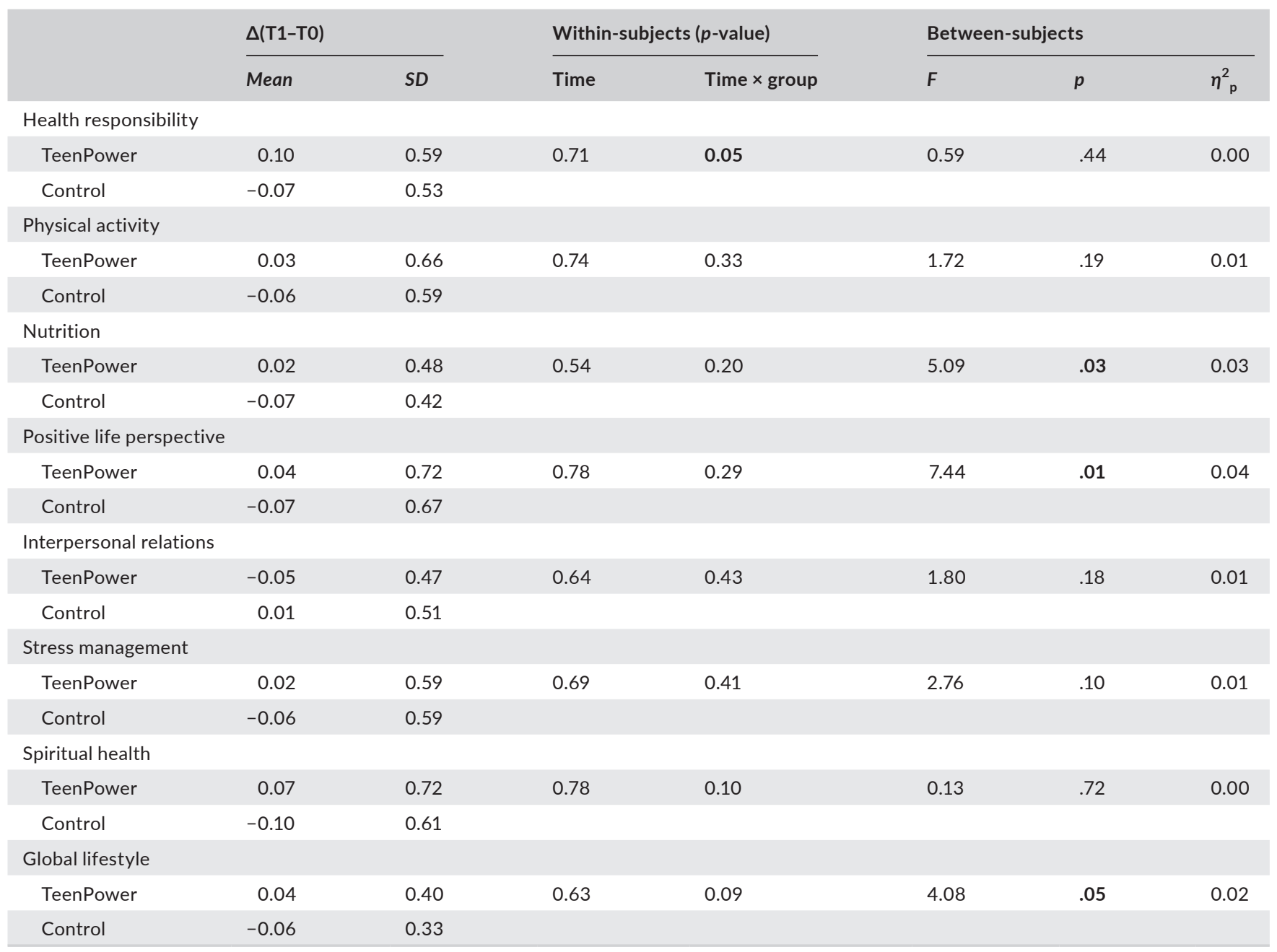

Abbreviations: $F$, ANOVA test statistic; $\eta_{p}^{2}$, partial eta squared.

Bold indicates statistically significant $p<.05$.

TABLE 3 Repeated measures analyses of the group effect within each school district: between-subjects analysis

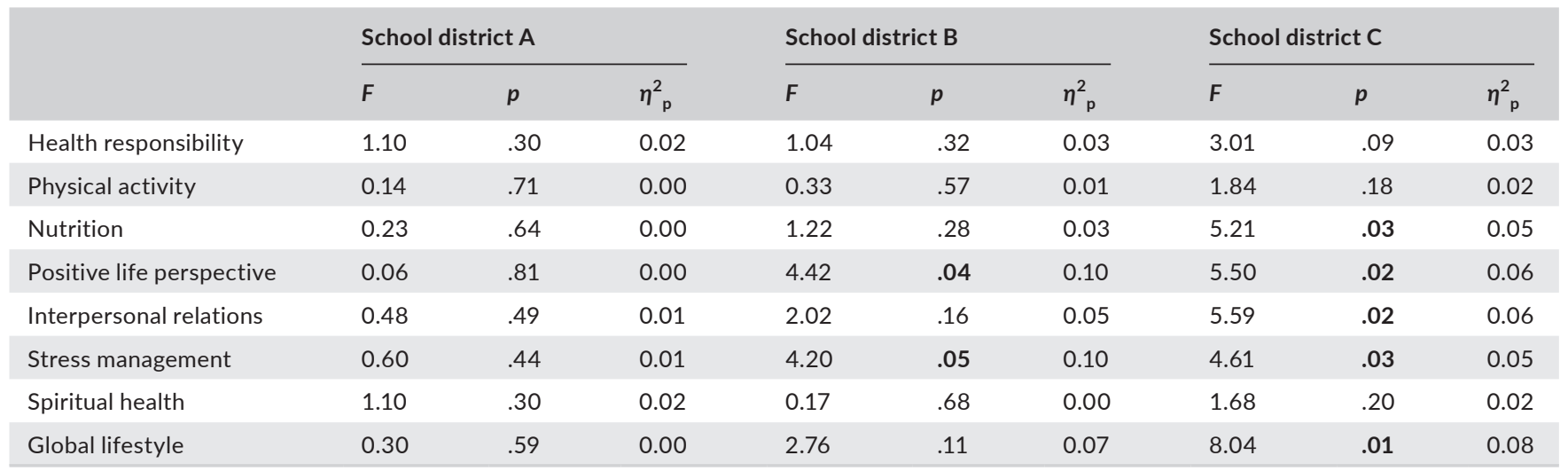

Abbreviations: $F$, ANOVA test statistic; $\eta_{p}^{2}$, partial eta squared.

Bold indicates statistically significant $p<.05$.

\section{4 | DISCUSSION}

This study aimed to evaluate the effectiveness of an adolescent mHealth intervention (TeenPower) when compared with a conventional school-based intervention, regarding the promotion of healthy lifestyles. Adolescence is the ideal lifetime to implement health promotion programmes (Banspach et al., 2016; Rasberry et al., 2017) as they spend most of their day at school, where they 
TABLE 4 Analysis of predictors of effectiveness in the TeenPower group

\begin{tabular}{|c|c|c|c|c|c|c|c|c|}
\hline & \multicolumn{8}{|c|}{$\Delta$ Lifestyle } \\
\hline Age $(r)$ & -.08 & .16 & .23 & .19 & .21 & $.40^{*}$ & .12 & .24 \\
\hline Gender $(t)$ & 0.17 & -0.06 & -0.23 & -1.67 & 0.20 & 0.45 & 0.04 & -0.19 \\
\hline eHealth literacy $(r)$ & .08 & .03 & -.05 & -.18 & -.08 & -.22 & .06 & -.06 \\
\hline
\end{tabular}

Abbreviations: ALP, adolescent lifestyle profile; F, ANOVA test statistic; HR, health responsibility; IR, interpersonal relations; N, nutrition; PA, physical activity; PLP, positive life perspective; $r$, Pearson correlation statistic; SH, spiritual health; SM, stress management; $t$, Student's $t$ test statistic.

$*_{p}<.01$.

adopt part of their lifestyle (Kelishadi \& Azizi-Soleiman, 2014). School-based health promotion programmes can have a major influence on the acquisition of healthy behaviours, including domains such as nutrition, physical activity, health responsibility, stress management, positive life perspective, spiritual health, and interpersonal relations (Ardic \& Esin, 2015).

The baseline evaluation of the adolescents' lifestyle showed that the domains with the lowest scores were the spiritual health and the health responsibility and the highest scores domains were the interpersonal relations and positive life perspective, similar to other studies (Kim \& Kim, 2018; Sousa, Gaspar, et al., 2015). It should be noted, however, that other researchers found higher lifestyle scores in the spiritual domain and health responsibility (Golmakani, Naghibi, Moharari, \& Esmaily, 2013; Shariferad, Shojaeezadeh, Tol, $\&$ Tavassoli, 2013) and lower scores in physical activity (Geok et al., 2015; Golmakani et al., 2013; Shariferad et al., 2013). Our data suggest that, although adolescents have good interpersonal relationships and a positive life perspective, they do not feel responsible for promoting their health.

Our results support the initial hypothesis that the mHealth intervention (TeenPower) is more effective than the standard school-based intervention in the promotion of healthy behaviours. The improvement of health behaviours by mHealth interventions had already been verified in previous studies (Guarneri \& Perego, 2017; Hervas, RuizCarrasco, Bravo, \& Mondejar, 2017). Our results show a significant time-group interaction in the health responsibility dimension, with a positive change in the experimental group. This positive effect of e-health interventions in the promotion of health responsibility is consistent with previous studies (Sousa, Fonseca, et al., 2015) and systematic reviews (An, Hayman, Park, Dusaj, \& Ayres, 2009; Nguyen et al., 2011; Sousa, 2014). Responsibility for their health should be a social and individual effort (Resnik, 2007) and this is one of the most common health promotion indicators pointed in previous studies (Ayres \& Pontes, 2018; Cohen, 2004).

Regarding the between-subjects effect, we found a small effect of the mHealth intervention (TeenPower) on nutrition, positive life perspective, and global lifestyle. The small effect might be related to the reduced time of the intervention (6 months), shorter than the previous studies (Kelishadi \& Azizi-Soleiman, 2014) and the limited exposure to the resources significant for the intervention, although all participants have periodically received reminder notifications sent through the platform (Sousa et al., 2019). Additionally, we must highlight the fact that the control group in the study used a structured intervention instead of being a 'traditional' control group without intervention. This could explain the small differences between the two groups (Wieland et al., 2012). The option for this control group was based on the intention to minimize the dropout rate and on ethical aspects. Furthermore, we chose to use mHealth as an add-on and not as a substitute of the standard intervention, assuming the importance of the face-to-face contact with health professionals (Fonseca, Prioste, Sousa, Gaspar, \& Machado, 2016). Interestingly, the mean scores of nutrition, positive life perspective, and global lifestyle decreased in the control group during the study period. These results seem to indicate that the standard school-based intervention was not able to improve or sustain the health behaviours against the stress of the school environment. Previous studies have shown that school demands are an important driver of stress in adolescents (Östberg, Plenty, Låftman, Modin, \& Lindfors, 2018).

In our study, the attrition rate of the mHealth intervention (TeenPower) participants was $37.9 \%$ because several adolescents were lost to follow-up or did not engage in the intervention. The limited adherence to the eHealth interventions directed to adolescents was already reported in previous studies (Sousa, Fonseca, et al., 2015). Indeed, a well-known limitation related to current mHealth interventions is app underuse. A previous report (Clement, 2019) revealed that a quarter of all app is used only once with a user retention rate of $32 \%$ for the first months of 2019 . Other authors reported retention rates in eHealth interventions ranging from 0.5\% (Eysenbach, 2005) to 93\% (Hammersley, Jones, \& Okely, 2016). Therefore, user engagement in mHealth interventions is considered as the main concern of this type of intervention (Taki et al., 2017). The adolescents' lifestyle changes in both intervention and control groups differed according to the school district. These results may be due to the typology of the region 
where schools are located, school dynamics and organization and even family involvement. Future studies should also focus on understanding the cultural and social influence of the school context in such interventions.

A secondary objective of the study was the predictors' analysis of the mHealth intervention effectiveness. We found that neither gender nor body image dissatisfaction or eHealth literacy presented significant influence in lifestyle changes in the TeenPower group. These findings do not support previous studies that stressed the importance of gender in health promotion, pointing gender differences in physical activity, nutrition, positive life perspective, and stress management (Scoloveno, 2017).

Despite several studies having identified the importance of health literacy in the promotion of healthy lifestyles (Liu, Yen, Chiou, \& Liao, 2009; Mamedov, Garaev, Korkmazov, \& Mirzabekova, 1988; Yang, Luo, \& Chiang, 2017), in our study, eHealth literacy was not a significant predictor of lifestyle changes. It is noteworthy that the baseline evaluation showed that adolescents presented eHealth literacy scores above the median of the scale.

The baseline evaluation of adolescents' body image dissatisfaction showed a small intention for weight loss. However, body image dissatisfaction did not significantly influence lifestyle change among the TeenPower participants. These results do not support the conclusions of previous studies (Coelho, Fonseca, Pinto, \& MourãoCarvalhal, 2016; Wilkosz, Chen, Kenndey, \& Rankin, 2011); however, it should be noted that these studies did not present an experimental design.

Only adolescent age has been confirmed as a significant predictor of the effectiveness of the mHealth intervention in improving stress management. It seems that older adolescents tended to present a significant increase in the ability to manage their stress after the mHealth intervention (TeenPower). These results confirmed the findings of previous studies that highlight the influence of adolescents' age in the development of stress management skills (Hampel, Meier, \& Kümmel, 2008; Lee et al., 2019; Monteiro, Balogun, \& Oratile, 2014).

Among the strengths of this study, we highlight its innovative character and contribution to the scientific knowledge in this domain since it is one of the few papers that evaluate an mHealth intervention for adolescents, based in case management. Moreover, it is important to mention the option for evaluating the intervention effectiveness in detriment of its efficacy. The effectiveness analysis is a more realistic approach that seeks to analyse the results under conditions closer to real life, allowing for greater heterogeneity in the sample (Sousa, Fonseca, et al., 2015). This reinforces the external validity of the study.

\section{1 | Limitations}

We acknowledge the existence of some limitations in this study, namely (a) the high attrition rate in the experimental group that could bias the effectiveness analysis and (b) only one self-reported measure was used to assess each psychosocial variable. The adolescents' answers may be biased by the social desirability, an aspect that we tried to minimize by the guarantee of anonymity and the use of a validated questionnaire; (c) the absence of randomization of adolescents to the experimental and control groups threaten the internal and external validity, compromising the generalization of the results. Bearing that in mind, baseline characteristics of both groups were evaluated concerning the homogeneity. Despite the significant differences between school districts, globally both groups may be considered comparable and homogeneous. Nevertheless, we are conscious that generalization of results should be done with caution; (d) the lack of long-term follow-up to assess the maintenance of the behavioural change and (e) the absence of data collection regarding the access frequency to the e-platform as a measure of user engagement are also limitations of these findings.

\section{5 | CONCLUSION}

Our findings provide support for the effectiveness of mHealth programmes for health promotion as an add-on to the standard interdisciplinary intervention. The mHealth intervention (TeenPower) presented significant impact on multiple lifestyle domains, such as health responsibility, nutrition, positive life perspective, and global lifestyle. For a better understanding of the power of mHealth interventions, these findings should be carefully evaluated in future studies including a long-run follow-up and a wider set of measures.

Further research is required to be able to identify the secondary outcomes of this intervention in the school context. The identification of those outcomes may facilitate future dissemination of the intervention at other institutions using the acquired strategies and knowledge, which included a wide range of stakeholders (health professionals, schools, and adolescents).

\section{ACKNOWLEDGEMENTS}

This study is on behalf of the TeenPower research group. We acknowledge the Polytechnic Institutes of Leiria, Santarém and Castelo Branco, the Municipality of Leiria (City Hall), and all members, institutions, and students involved in the project. We also wish to acknowledge the contribution of the nursing staff of 'UCC da Marinha Grande', 'UCC Arnaldo Sampaio', and 'UCC de Santarém', and the contribution of all academic staff of the following schools: Agrupamento de Escolas Marinha Grande-Poente, Agrupamento de Escolas Alexandre Herculano-Santarém, and Escola Secundária Afonso Lopes Vieira.

\section{CONFLICTS OF INTEREST}

The authors report no conflicts of interest.

\section{AUTHOR CONTRIBUTIONS}

PS, RM, CR, SD, PG, MD, LL, and RF: Made substantial contributions to conception and design, or acquisition of data, or analysis 
and interpretation of data; PS, RM, CR, SD, PG, MD, LL, and RF: Involved in drafting the manuscript or revising it critically for important intellectual content; PS, RM, CR, SD, PG, MD, LL, and RF: Given final approval of the version to be published. Each author should have participated sufficiently in the work to take public responsibility for appropriate portions of the content; PS, RM, CR, SD, PG, MD, LL, and RF: Agreed to be accountable for all aspects of the work in ensuring that questions related to the accuracy or integrity of any part of the work are appropriately investigated and resolved.

\section{ORCID}

Pedro Sousa (iD https://orcid.org/0000-0002-6313-532X

Pedro J. S. Gaspar (ID https://orcid.org/0000-0001-8996-4356

Maria dos Anjos Dixe iD https://orcid.org/0000-0001-9035-8548

\section{REFERENCES}

Afshin, A., Babalola, D., Mclean, M., Yu, Z., Ma, W., Chen, C.-Y., ... Mozaffarian, D. (2016). Information technology and lifestyle: A systematic evaluation of internet and mobile interventions for improving diet, physical activity, obesity, tobacco and alcohol use. Journal of the American Heart Association, 5(9), e003058. https://doi.org/10.1161/ JAHA.115.003058

Ahern, D., Phalen, J., Le, L., \& Goldman, R. (2007). Childhood obesity prevention and reduction: Role of eHealth. Boston, MA: Health E-Technologies.

An, J., Hayman, L., Park, Y., Dusaj, T., \& Ayres, C. (2009). Web-based weight management programs for children and adolescents: A systematic review of randomized controlled trial studies. Advances in Nursing Science, 32(3), 222-240. https://doi.org/10.1097/ANS.0b013 e3181b0d6ef

Ardic, A., \& Esin, M. N. (2015). The adolescent lifestyle profile scale: Reliability and validity of the Turkish version of the instrument. Journal of Nursing Research, 23(1), 33-40. https://doi.org/10.1097/ jnr.0000000000000052

Ayres, C. G., \& Pontes, N. M. (2018). Use of theory to examine health responsibility in urban adolescents. Journal of Pediatric Nursing, 38, 40-45. https://doi.org/10.1016/j.pedn.2017.09.011

Baños, R. M. (2011). Improving childhood obesity treatment using new technologies: The ETIOBE system. Clinical Practice \& Epidemiology in Mental Health, 7(1), 62-66. https://doi.org/10.2174/1745017901 107010062

Banspach, S., Zaza, S., Dittus, P., Michael, S., Brindis, C. D., \& Thorpe, P. (2016). CDC grand rounds: Adolescence - Preparing for lifelong health and wellness. Morbidity and Mortality Weekly Report, 65(30), 759-762. https://doi.org/10.15585/mmwr.mm6530a2

Baulch, J., Chester, A., \& Brennan, L. (2008). Treatment alternatives for overweight and obesity: The role of online interventions. Behaviour Change, 25(1), 1-14. https://doi.org/10.1375/bech.25.1.1

Bert, F., Giacometti, M., Gualano, M. R., \& Siliquini, R. (2014). Smartphones and health promotion: A review of the evidence. Journal of Medical Systems, 38(1), 9995. https://doi.org/10.1007/ s10916-013-9995-7

Calvillo, J., Román, I., \& Roa, L. M. (2015). How technology is empowering patients? A literature review. Health Expectations, 18(5), 643-652. https://doi.org/10.1111/hex.12089

Cameron, J. D., Ramaprasad, A., \& Syn, T. (2017). An ontology of and roadmap for mHealth research. International Journal of Medical Informatics, 100, 16-25. https://doi.org/10.1016/j.ijmedinf.2017.01.007

Chen, J.-L., \& Wilkosz, M. E. (2014). Efficacy of technology-based interventions for obesity prevention in adolescents: A systematic review.
Adolescent Health, Medicine and Therapeutics, 5, 159-170. https://doi. org/10.2147/ahmt.s39969

Clement, J. (2019). Mobile application user retention rate worldwide from 2012 to 2019. In: Statista - The Statistics Portal. Retrieved from https://www.statista.com/statistics/751532/worldwide-application-user-retention-rate/

CMSA. (2016). Standards of practice for case management. Retrieved from https://www.miccsi.org/wp-content/uploads/2017/03/CMSAStandards-2016.pdf

Coelho, E. M., Fonseca, S. C., Pinto, G. S., \& Mourão-Carvalhal, M. I. (2016). Factors associated with body image dissatisfaction in Portuguese adolescents: Obesity, sports activity and TV watching. Motricidade, 12(2), 18-26. https://doi.org/10.6063/motricidade.6277

Coelho, E. M., Padez, C., Moreira, P., Rosado, V., \& Mourão-Carvalhal, I. (2013). BMI and self-perceived body shape in Portuguese children. Revista de Psicologia del Deporte, 22(2), 371-376.

Cohen, S. (2004). Social relationships and health. American Psychologist, 59(8), 676-684. https://doi.org/10.1037/0003-066X.59.8.676

Collins, M. E. (1991). Body figure perceptions and preferences among preadolescent children. International Journal of Eating Disorders, 10(2), 199-208. https://doi.org/10.1002/1098-108X(19910 3)10:2<199:AID-EAT2260100209>3.0.CO;2-D

Courtenay, M., Castro-Sánchez, E., Deslandes, R., Hodson, K., Lim, R., Morris, G., ... Weiss, M. (2018). Defining antimicrobial stewardship competencies for undergraduate health professional education in the United Kingdom: A study protocol. Journal of Interprofessional Care, 32(5), 638-640. https://doi.org/10.1080/13561820.2018.1463200

Craig, P., Dieppe, P., Macintyre, S., Michie, S., Nazareth, I., \& Petticrew, M. (2013). Developing and evaluating complex interventions: The new Medical Research Council guidance. International Journal of Nursing Studies, 50(5), 587-592. https://doi.org/10.1016/j.ijnurstu.2012.09.010

Danaher, B. G., Brendryen, H., Seeley, J. R., Tyler, M. S., \& Woolley, T. (2015). From black box to toolbox: Outlining device functionality, engagement activities and the pervasive information architecture of mHealth interventions. Internet Interventions, 2(1), 91-101. https:// doi.org/10.1016/j.invent.2015.01.002

Enwald, H. P. K., \& Huotari, M. L. A. (2010). Preventing the obesity epidemic by second generation tailored health communication: An interdisciplinary review. Journal of Medical Internet Research, 12(2), e24. https://doi.org/10.2196/jmir.1409

European Commission. (2014). Green paper on mobile health ('m-health'). Brussels. Retrieved from https://ec.europa.eu/digital-agenda/en/ news/green-paper-mobile-health-mhealth

Eysenbach, G. (2005). The law of attrition. Journal of Medical Internet Research, 7(1), e11. https://doi.org/10.2196/jmir.7.1.e11

Fedele, D. A., Cushing, C. C., Fritz, A., Amaro, C. M., \& Ortega, A. (2017). Mobile health interventions for improving health outcomes in youth a meta-analysis. JAMA Pediatrics, 171(5), 461-469. https://doi. org/10.1001/jamapediatrics.2017.0042

Fonseca, H., Prioste, A., Sousa, P., Gaspar, P., \& Machado, M. do C., (2016). Effectiveness analysis of an internet-based intervention for overweight adolescents: Next steps for researchers and clinicians. BMC Obesity, 3(1), 15. https://doi.org/10.1186/S40608-016-0094-4

Geok, S. K., Yusof, A., Lam, S. K., Japar, S., Leong, O. S., \& Fauzee, M. S. O. (2015). Physical activity and health-promoting lifestyle of student nurses in Malaysia. Journal of Biosciences and Medicines, 3(3), 78-87. https://doi.org/10.4236/jbm.2015.33012

Golmakani, N., Naghibi, F., Moharari, F., \& Esmaily, H. (2013). Health promoting life style and its related factors in adolescent girls. Journal of Midwifery and Reproductive Health, 1(1), 42-49.

Guarneri, M. R., Brocca, M. D., \& Piras, L. (2017). Patient's empowerment and behaviour change: Complementary approaches in EU projects PALANTE and PEGASO. In: K. Giokas, L. Bokor, \& F. Hopfgartner (Eds.), eHealth $360^{\circ}$ (pp. 359-369). Cham, Switzerland: Springer. https:// doi.org/10.1007/978-3-319-49655-9_43 
Guarneri, M. R., \& Perego, P. (2017). Games and gamification for healthy behaviours: The experience of PEGASO fit 4 future. In: K. Giokas, L. Bokor, \& F. Hopfgartner (Eds.), eHealth $360^{\circ}$ (pp. 100-109). Cham, Switzerland: Springer. https://doi. org/10.1007/978-3-319-49655-9_14

Hahn, S. (2012). Understanding noninferiority trials. Korean Journal of Pediatrics, 55(11), 403-407. https://doi.org/10.3345/ kjp.2012.55.11.403

Hammersley, M. L., Jones, R. A., \& Okely, A. D. (2016). Parent-focused childhood and adolescent overweight and obesity ehealth interventions: A systematic review and meta-analysis. Journal of Medical Internet Research, 18(7), e203. https://doi.org/10.2196/jmir.5893

Hampel, P., Meier, M., \& Kümmel, U. (2008). School-based stress management training for adolescents: Longitudinal results from an experimental study. Journal of Youth and Adolescence, 37(8), 1009-1024. https://doi.org/10.1007/s10964-007-9204-4

Hauerslev, M., \& Allen, L. (2018). Young people and noncommunicable diseases - Vulnerable to disease, vital for change. International Journal of Noncommunicable Diseases, 3(2), 45. https://doi.org/10.4103/jncd. jncd_7_18

Hervas, R., Ruiz-Carrasco, D., Bravo, J., \& Mondejar, T. (2017). Gamification mechanics for behavioral change: A systematic review and proposed taxonomy. In: ACM International Conference Proceeding Series (pp. 395-404). https://doi.org/10.1145/31548 62.3154939

Jackson, A. D., Kirwan, L., Gibney, S., Jeleniewska, P., Fletcher, G., \& Doyle, G. (2019). Associations between health literacy and patient outcomes in adolescents and young adults with cystic fibrosis. European Journal of Public Health, ckz148, https://doi.org/10.1093/ eurpub/ckz148

Jacobs, R., Lou, J., Ownby, R., \& Caballero, J. (2016). A systematic review of eHealth interventions to improve health literacy. Health Informatics Journal, 22(2), 81-98. https://doi.org/10.1177/1460458214534092

Karlsson, L., Andersson, M., \& Johansson, J. (2014). Empowering adolescents to engage in healthy behaviours through peer leadership training in the townships of Cape Town. International Journal of Child, Youth and Family Studies, 5(2), 258-278. https://doi.org/10.18357/ ijcyfs.karlssonle. 522014

Kelishadi, R., \& Azizi-Soleiman, F. (2014). Controlling childhood obesity: A systematic review on strategies and challenges. Journal of Research in Medical Sciences: The Official Journal of Isfahan University of Medical Sciences, 19(10), 993-1008.

Kim, H., \& Xie, B. (2017). Health literacy in the eHealth era: A systematic review of the literature. Patient Education and Counseling, 100(6), 1073-1082. https://doi.org/10.1016/j.pec.2017.01.015

Kim, J., \& Park, H. A. (2012). Development of a health information technology acceptance model using consumers' health behavior intention. Journal of Medical Internet Research, 14(5), e133. https://doi. org/10.2196/jmir.2143

Kim, M. Y., \& Kim, Y. J. (2018). What causes health promotion behaviors in college students? The Open Nursing Journal, 12(1), 106-115. https:// doi.org/10.2174/1874434601812010106

Lee, R. L. T., Chien, W. T., Tanida, K., Takeuchi, S., Rutja, P., Kwok, S. W. H., \& Lee, P. H. (2019). The association between demographic characteristics, lifestyle health behaviours and quality of life among adolescents in Asia Pacific region. International Journal of Environmental Research and Public Health, 16(13), 2324. https://doi.org/10.3390/ ijerph16132324

Liu, C. H., Yen, H. W., Chiou, S. Y., \& Liao, L. L. (2009). Enhancing professional competency and healthy lifestyles of middle school health educators through eHealth technology. Taiwan Journal of Public Health, 28(6), 475-490.

Mamedov, Y. D., Garaev, G. S., Korkmazov, B. M., \& Mirzabekova, F. I. (1988). Effect of a terrilytin-nicotinic acid mixture on the structural and functional state of the myocardium in experimental ischemia.
Bulletin of Experimental Biology and Medicine, 105(5), 740-742. https:// doi.org/10.1007/BF00841552

Modi, A., Zeller, M., Xanthakos, S., Jenkins, T., \& Inge, T. (2013). Adherence to vitamin supplementation. Jacobs Journal of Food and Nutrition, 516(7530), 267-271. https://doi.org/10.1038/nature13736.Tyrosine

Monteiro, N. M., Balogun, S. K., \& Oratile, K. N. (2014). Managing stress: The influence of gender, age and emotion regulation on coping among university students in Botswana. International Journal of Adolescence and Youth, 19(2), 153-173. https://doi.org/10.1080/02673 843.2014.908784

Nguyen, B., Kornman, K. P., \& Baur, L. A. (2011). A review of electronic interventions for prevention and treatment of overweight and obesity in young people. Obesity Reviews, 12(501), e298-e314. https:// doi.org/10.1111/j.1467-789X.2010.00830.x

Orji, R., Tondello, G. F., \& Nacke, L. E. (2018). Personalizing persuasive strategies in gameful systems to gamification user types. In: Conference on Human Factors in Computing Systems - Proceedings ( $p$. 435). ACM. https://doi.org/10.1145/3173574.3174009

Östberg, V., Plenty, S., Låftman, S. B., Modin, B., \& Lindfors, P. (2018). School demands and coping resources-associations with multiple measures of stress in mid-adolescent girls and boys. International Journal of Environmental Research and Public Health, 15(10), 2143. https://doi.org/10.3390/ijerph15102143

Rasberry, C. N., Tiu, G. F., Kann, L., McManus, T., Michael, S. L., Merlo, C. L., ... Ethier, K. A. (2017). Health-related behaviors and academic achievement among high school students - United States, 2015. Morbidity and Mortality Weekly Report, 66, 921-927. https://doi. org/10.15585/mmwr.mm6635a1

Resnik, D. B. (2007). Responsibility for health: Personal, social and environmental. Journal of Medical Ethics, 33(8), 444-445. https://doi. org/10.1136/jme.2006.017574

Sardi, L., Idri, A., \& Fernández-Alemán, J. L. (2017). A systematic review of gamification in e-Health. Journal of Biomedical Informatics, 71, 31 48. https://doi.org/10.1016/j.jbi.2017.05.011

Schoeppe, S., Alley, S., Rebar, A. L., Hayman, M., Bray, N. A., Van Lippevelde, W., ... Vandelanotte, C. (2017). Apps to improve diet, physical activity and sedentary behaviour in children and adolescents: A review of quality, features and behaviour change techniques. International Journal of Behavioral Nutrition and Physical Activity, 14(1), 83. https://doi.org/10.1186/s12966-017-0538-3

Scoloveno, R. (2017). Gender differences in health practices in middle adolescent boys and girls. International Journal of Nursing \& Clinical Practices, 4(1), 268. https://doi.org/10.15344/2394-4978/2017/268

Sharif, I., \& Blank, A. (2010). Relationship between child health literacy and body mass index in overweight children. Patient Education and Counseling, 79(1), 43-48. https://doi.org/10.1016/j.pec.2009.07.035

Shariferad, G., Shojaeezadeh, D., Tol, A., \& Tavassoli, E. (2013). Healthpromoting lifestyle and quality of life among undergraduate students at School of Health, Isfahan University of Medical Sciences. Journal of Education and Health Promotion, 2(1), 11. https://doi. org/10.4103/2277-9531.108006

Simons, D., De Bourdeaudhuij, I., Clarys, P., De Cocker, K., Vandelanotte, C., \& Deforche, B. (2018). A smartphone app to promote an active lifestyle in lower-educated working young adults: Development, usability, acceptability and feasibility study. JMIR mHealth and uHealth, 6(2), e44. https://doi.org/10.2196/mhealth.8287

Sousa, P. (2014). Efetividade dos programas de intervenção de e-Saúde em adolescentes obesos. Pensar Enfermagem, 18(1), 27-39.

Sousa, P., Duarte, E., Ferreira, R., Esperança, A., Frontini, R., SantosRocha, R., ... Marques, N. (2019). An mHealth intervention programme to promote healthy behaviours and prevent adolescent obesity (TeenPower): A study protocol. Journal of Advanced Nursing, 75(3), 683-691. https://doi.org/10.1111/jan.13905

Sousa, P., Fonseca, H., Gaspar, P., \& Gaspar, F. (2015). Controlled trial of an Internet-based intervention for overweight teens (Next.Step): 
Effectiveness analysis. European Journal of Pediatrics, 174(9), 11431157. https://doi.org/10.1007/s00431-015-2502-z

Sousa, P., Gaspar, P., Fonseca, H., Hendricks, C., \& Murdaugh, C. (2015). Health promoting behaviors in adolescence: Validation of the Portuguese version of the adolescent lifestyle profile. Jornal de Pediatria, 91(4), 358-365. https://doi.org/10.1016/j. jped.2014.09.005

Styne, D. M., Arslanian, S. A., Connor, E. L., Farooqi, I. S., Murad, M. H., Silverstein, J. H., \& Yanovski, J. A. (2017). Pediatric obesity-assessment, treatment and prevention: An endocrine society clinical practice guideline. Journal of Clinical Endocrinology and Metabolism, 102(3), 709-757. https://doi.org/10.1210/jc.2016-2573

Taki, S., Lymer, S., Russell, C. G., Campbell, K., Laws, R., Ong, K.-L., ... Denney-Wilson, E. (2017). Assessing user engagement of an mHealth intervention: Development and implementation of the growing healthy app engagement index. JMIR mHealth and uHealth, 5(6), e89. https://doi.org/10.2196/mhealth.7236

Tate, E. B., Spruijt-Metz, D., O'Reilly, G., Jordan-Marsh, M., Gotsis, M., Pentz, M. A., \& Dunton, G. F. (2013). mHealth approaches to child obesity prevention: Successes, unique challenges and next directions. Translational Behavioral Medicine, 3(4), 406-415. https://doi. org/10.1007/s13142-013-0222-3

Tomás, C., Queirós, P., \& Ferreira, T. (2014). Análise das propriedades psicométricas da versão portuguesa de um instrumento de avaliação de e-Literacia em Saúde. Revista de Enfermagem Referência, 4(2), 19-28. https://doi.org/10.12707/RIV14004

Turner, T., Spruijt-Metz, D., Wen, C. K. F., \& Hingle, M. D. (2015). Prevention and treatment of pediatric obesity using mobile and wireless technologies: A systematic review. Pediatric Obesity, 10(6), 403-406. https://doi.org/10.1111/ijpo.12002

van Middelkoop, M., Ligthart, K. A. M., Paulis, W. D., van Teeffelen, J., Kornelisse, K., \& Koes, B. W. (2017). A multidisciplinary intervention programme for overweight and obese children in deprived areas. Family Practice, 34(6), 702-707. https://doi.org/10.1093/fampra/ $\mathrm{cm} \times 056$
Velickovski, F., Orte, S., Sola, M., Tabozzi, S. A., \& Lafortuna, C. L. (2017). Detection and assessment of behaviours associated with the risk of obesity in adolescents. In: K. Giokas, L. Bokor, \& F. Hopfgartner (Eds.), eHealth $360^{\circ}$ (pp. 253-258). Cham, Switzerland: Springer. https://doi.org/10.1007/978-3-319-49655-9_33

WHO. (2012). Prioritizing areas for action in the field of population-based prevention of childhood obesity: A set of tools for member states to determine and identify priority areas for action. Geneva, Switzerland: World Health Organization Press, 23(s5), 83. https://doi.org/10.1038/sj.ijo.0800994

WHO. (2018). Global action plan on physical activity 2018-2030: More active people for a healthier world. Geneva, Switzerland: World Health Organization. Retrieved from https://apps.who.int/iris/handl e/10665/272722

Wieland, L. S., Falzon, L., Sciamanna, C. N., Trudeau, K. J., Brodney Folse, S., Schwartz, J. E., \& Davidson, K. W. (2012). Interactive computer-based interventions for weight loss or weight maintenance in overweight or obese people. Cochrane Database of Systematic Reviews, 8 , CD007675. https://doi.org/10.1002/14651858.cd007675.pub2

Wilkosz, M.E., Chen, J.L., Kenndey, C., \& Rankin, S. (2011). Body dissatisfaction in California adolescents. Journal of the American Academy of Nurse Practitioners, 23(2), 101-109. https://doi.org/10.1111/j.1745-7599.2010.00586.x

Yang, S. C., Luo, Y. F., \& Chiang, C. H. (2017). The associations among individual factors, eHealth literacy and health-promoting lifestyles among college students. Journal of Medical Internet Research, 19(1), e15. https://doi.org/10.2196/jmir.5964

How to cite this article: Sousa P, Martinho R, Reis $\mathrm{Cl}$, et al. Controlled trial of an mHealth intervention to promote healthy behaviours in adolescence (TeenPower):

Effectiveness analysis. J Adv Nurs. 2020;00:1-12. https://doi. org/10.1111/jan.14301

The Journal of Advanced Nursing (JAN) is an international, peer-reviewed, scientific journal. JAN contributes to the advancement of evidence-based nursing, midwifery and health care by disseminating high quality research and scholarship of contemporary relevance and with potential to advance knowledge for practice, education, management or policy. JAN publishes research reviews, original research reports and methodological and theoretical papers.

For further information, please visit JAN on the Wiley Online Library website: www.wileyonlinelibrary.com/journal/jan

Reasons to publish your work in JAN:

- High-impact forum: the world's most cited nursing journal, with an Impact Factor of 1.998 - ranked 12/114 in the 2016 ISI Journal Citation Reports $@$ (Nursing (Social Science)).

- Most read nursing journal in the world: over 3 million articles downloaded online per year and accessible in over 10,000 libraries worldwide (including over 3,500 in developing countries with free or low cost access).

- Fast and easy online submission: online submission at http://mc.manuscriptcentral.com/jan.

- Positive publishing experience: rapid double-blind peer review with constructive feedback.

- Rapid online publication in five weeks: average time from final manuscript arriving in production to online publication.

- Online Open: the option to pay to make your article freely and openly accessible to non-subscribers upon publication on Wiley Online Library, as well as the option to deposit the article in your own or your funding agency's preferred archive (e.g. PubMed). 